\title{
THE DYNAMIC PARTICULARITIES OF CONTOUR PLOUGHING
}

\author{
Judit PÁSZTOR, ${ }^{1}$ Izolda POPA-MÜLLER ${ }^{3}$
}

Sapientia Hungarian University of Transylvania, Târgu-Mureș, Faculty of Technical and Human Sciences, Department of Mechanical Engineering, Târgu-Mureș, Romania

${ }^{1}$ pjudit@ms.sapientia.ro

${ }^{2}$ ipmuller@ms.sapientia.ro

\begin{abstract}
The plough is the basic machine for soil work. It is usually connected to the tractor by means of a suspension system. The suspension system is a bar-shaped arm system fixed to the tractor frame, which fixes and raises the attached machine in three points. Its role is significant. Single-sided ploughing on slopes creates some special situations. This phenomenon was observed during a plowing competition and in this paper we look for solutions related to this topic.
\end{abstract}

Keywords: Ploughing, plough, contour line on slope, dynamics.

\section{Introduction}

When observing the ploughing along a terrain, we have found that when the furrow is turned uphill, the movement of the machine is less rough and the head of the power machine maintains the direction easily. When the fur-row is turned downwards, the driver of the tractor cannot maintain the direction; the power machine is very difficult to steer. The phenomenon was observed during a ploughing competition, the situation appeared similar in most machine units. We decided to look for an answer to this phenomenon.

It can be assumed that in such a competition, the competitors are providing the best possible machine setup.

We assumed that this phenomenon was caused by the new forces from the sloping position of the contour ploughing. The three-point linkage that implements the tractor-ploughing units manifests these forces

\subsection{The three-point linkage system and its role in the operation of the suspended machine}

The three-point linkage system attaches the machine to the tractor.

It plays a role in the operation of the tractor-machine group, in towing, in increasing the towing force and in some settings of the attached machine.

The three-point suspension system includes an arm system and a lifting device.

The arm system consists of two lower drawbars 1 , two suspension rods 2, two lifting arms 3, which are connected by the lifting shaft 4 , and a support arm 5. The lower link arms are secured by the tensioning elements 6 .

The lifting mechanism includes a hydraulic pump, a control valve and a hydraulic cylinder. The hydraulic pump rotates the lifting shaft 4 (Figure.1.).

The three-point linkage system can be considered as a spatial rod mechanism (Figure 2.). The function of the suspension sys- 


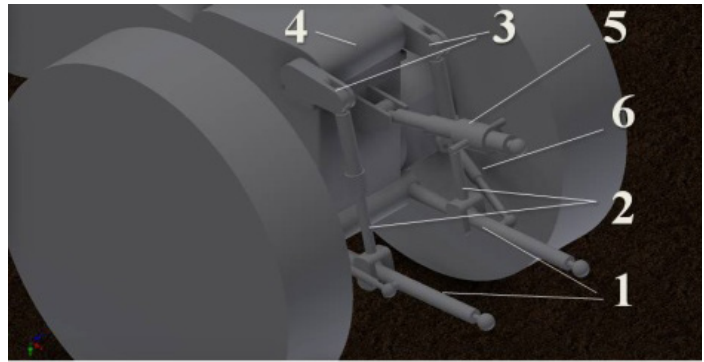

Figure 1. The construction of the three-point linkage system

tem is to unify the tractor-machine group [1]. Prolonging the lower drawbar arms towards the front of the tractor these intersect in the PFH point, which is considered the horizontal instantaneous rotation point (Figure 2.). The PFH horizontal instantaneous rotation point's recommended position is on the center line of the tractor. By varying the length of the tensioning chains, it is possible to achieve the desired position in the horizontal plane.

The upper support arm intersects the lower drawbars plane in point PFV, the vertical instantaneous rotation point. The traction force of the tractor is situated here. This point must be on the longitudinal centerline of the tractor when towing.
By changing the length of the arms with a spindle, the instantaneous rotation points can be moved during towing and work. Thus, the forces during the towing will be balanced.

\subsection{The plough and the applied forces}

The plough turns the soil. During its work, it cuts the ground vertically and horizontally, raises it and turns it to its right side, transporting the soil from its original position.

The plough-group works effectively if each plough is parallel to the ground surface, and works at the same depth. This can be achieved by proper adjustment of the three-point linkage.

The forces on the plough body are shown in Figure 3.

$$
\underline{\boldsymbol{F}}=\left[\begin{array}{c}
F_{x} \\
F_{y} \\
F_{z}
\end{array}\right]=\left[\begin{array}{c}
-k_{0} \cdot a \cdot b \cdot n \\
F_{x} \operatorname{tg} \alpha \\
-F_{x} \operatorname{tg} \beta
\end{array}\right]
$$

where:

$k_{o}$ is the specific soil resistance $\left[\mathrm{N} / \mathrm{m}^{2}\right]$;

$a$ the depth of ploughing [m];

$b$ the width of the plough [m];

$\alpha, \beta$ the angles of moldboard [ ${ }^{\circ}$ ].

During ploughing, the right-hand wheels of the power machine trail the furrow cut in the previous grip. Therefore the wheel axle is tilted with

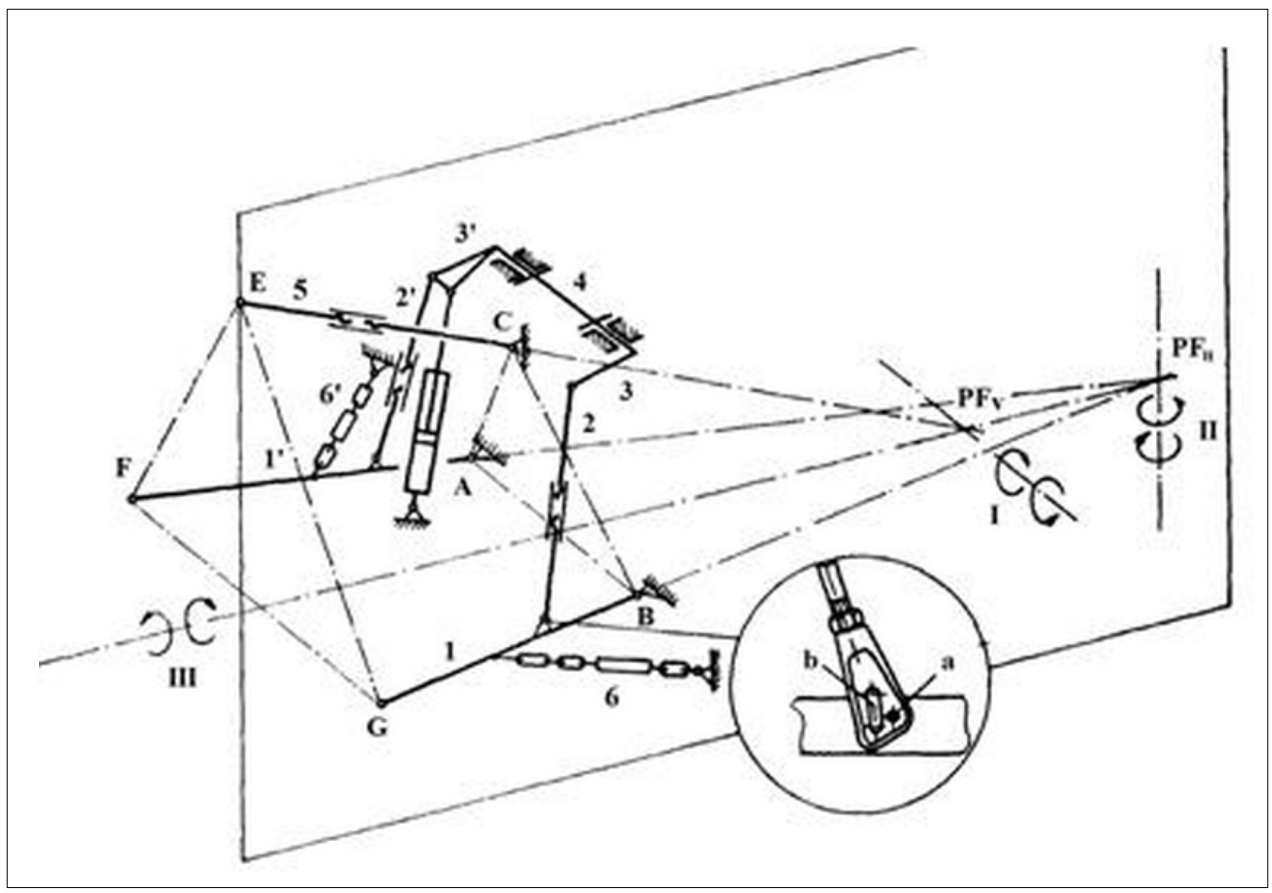

Figure 2. The mechanism of the three-point linkage system [1] 

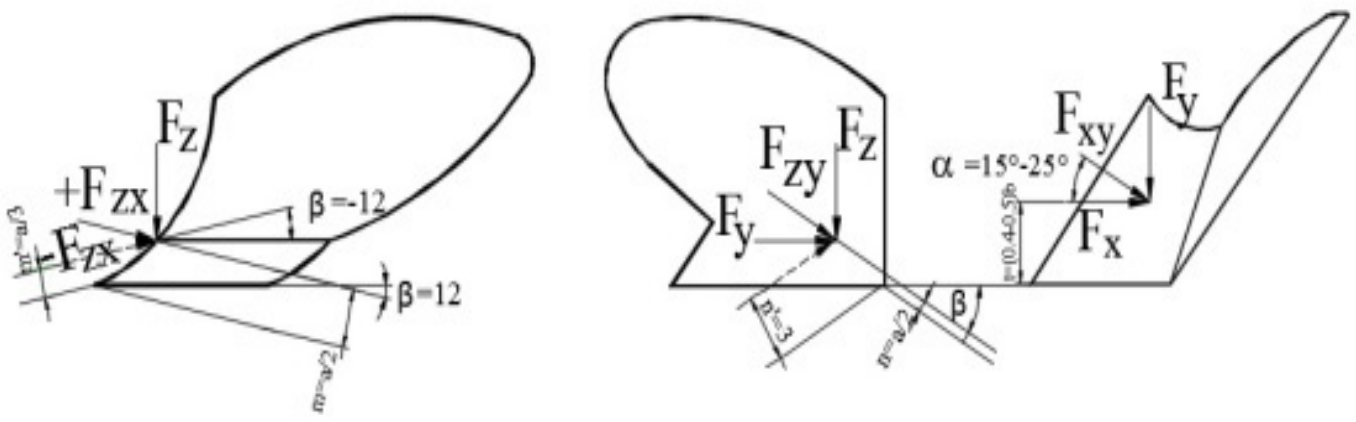

Figure 3. The forces on the plough body [2]

an angle $\delta$ On flat ground, its value is given only by the position of the wheels (Figure 4.).

\section{The particularity of contour ploug- hing with the suspended plough}

The plough moves the soil from the sides to the center. Thus, during contour ploughing, if the plough turns the furrow in uphill, when it comes back cutting the next row, it will turn the furrow in downhill (Figure 5.). In order to create the conditions for a better storing of the rain fall and diminishing the soil erosion, the turning of the furrows is recommended to be done in uphill. This can be accomplished with a lot of unloaded running. This makes inevitable the turning in downhill too.

\subsection{Mathematical models}

\subsubsection{Modelling of soil resistance on the plough}

The position of the tractor modifies by ploughing along the contour line. As a consequence the angle $\delta$ of the axis changes, (Figure 6.).

Since the plough is working on a $\gamma$-angle tilted slope, during the uphill and downhill turning of the furrow, the action of the soil resistance forces acting on the plough changes too. This is mathematically expressed by the rotation of the coordinate system, [3], [4]. The frame $O X Y Z$ can be arbitrarily chosen. However, the simplest variant is where the plough-body rotates along the axis OX with the angles $\delta$ ' and $\delta$ " ", (Figure 6. and 7.).

When the plough turns the furrow uphill the action of forces is shown on Figure 6 .

The transformation matrix Mx' is [4]:

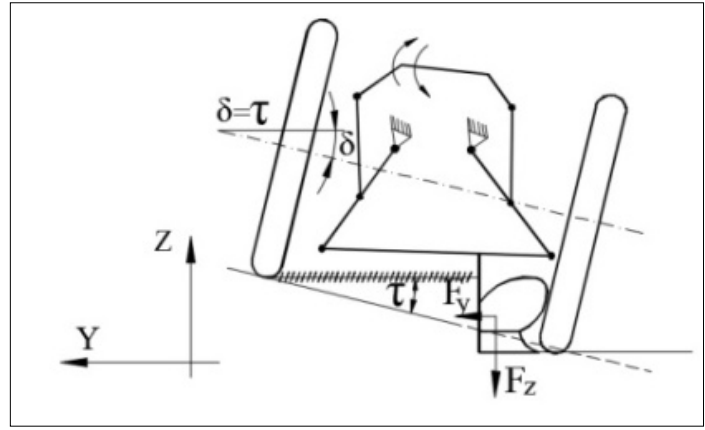

Figure 4. The position of the tractor and plough during plowing

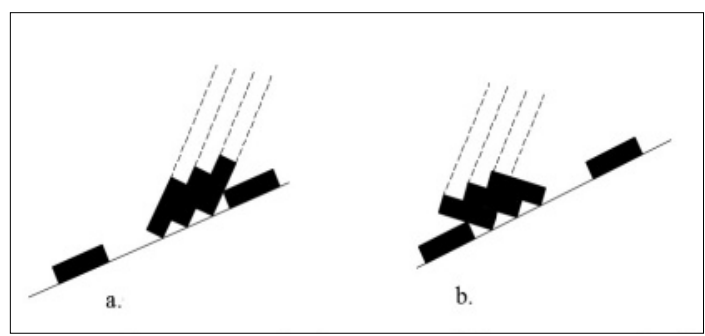

Figure 5. Soil rotating cases in contour ploughing, a-correct furrow turning, $b$ - incorrect furrow turning

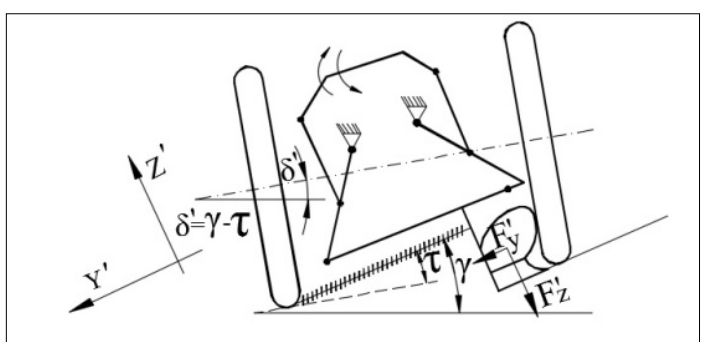

Figure 6. The position of the machine when the furrow is turned uphill 


$$
\boldsymbol{M}_{\boldsymbol{x}}{ }^{\prime}=\left[\begin{array}{cccc}
1 & 0 & 0 & 0 \\
0 & \cos \delta^{\prime} & -\sin \delta^{\prime} & 0 \\
0 & \sin \delta^{\prime} & \cos \delta^{\prime} & 0 \\
0 & 0 & 0 & 1
\end{array}\right]
$$

where $\delta$ ' is the angle of inclination of the wheel axle during the turning uphill the furrow. Its value can be calculated as follows:

$$
\delta^{\prime}=\tau-\gamma
$$

Reactive forces acting on the plough will take new values primed by the matrix formula:

$$
\boldsymbol{F}^{\prime}=\boldsymbol{L}_{\boldsymbol{x}}{ }^{\prime} \cdot \boldsymbol{F}
$$

where $\mathbf{L}_{\mathbf{x}}{ }^{\prime}$ is the rotational submatrix of $\mathbf{M}_{\mathbf{x}}{ }^{\prime}$

$$
\underline{\boldsymbol{F}}^{\prime}=\left[\begin{array}{c}
F_{x}^{\prime} \\
F_{y}^{\prime} \\
F_{z}^{\prime}
\end{array}\right]=\left[\begin{array}{c}
F_{x} \\
F_{y} \cos \delta^{\prime}-F_{z} \sin \delta^{\prime} \\
F_{y} \sin \delta^{\prime}+F_{z} \cos \delta^{\prime}
\end{array}\right] .
$$

When the furrow is turned downhill, the position of the machine is shown on Figure 7.

The transformation matrix $\mathbf{M}_{\mathrm{x}}$ ” becomes[4]:

$$
\boldsymbol{M}_{x}^{\prime \prime}=\left[\begin{array}{cccc}
1 & 0 & 0 & 0 \\
0 & \cos \delta^{\prime \prime} & \sin \delta^{\prime \prime} & 0 \\
0 & -\sin \delta^{\prime \prime} & \cos \delta^{\prime \prime} & 0 \\
0 & 0 & 0 & 1
\end{array}\right]
$$

where $\delta$ ” is the angle of inclination on the wheel axle. Its value is:

$$
\delta^{\prime \prime}=\tau+\gamma \text {. }
$$

The reactive forces take new values:

$$
F^{\prime \prime}=L^{\prime \prime} \cdot \boldsymbol{F} \text {, }
$$

$$
\underline{\boldsymbol{F}}^{\prime \prime}=\left[\begin{array}{c}
F^{\prime \prime}{ }^{x} \\
F^{\prime \prime}{ }_{y} \\
F^{\prime \prime}{ }_{z}
\end{array}\right]=\left[\begin{array}{c}
F_{x} \\
F_{y} \cos \delta^{\prime \prime}+F_{z} \sin \delta^{\prime} \\
-F_{y} \sin \delta^{\prime \prime}+F_{z} \cos \delta^{\prime \prime}
\end{array}\right] .
$$

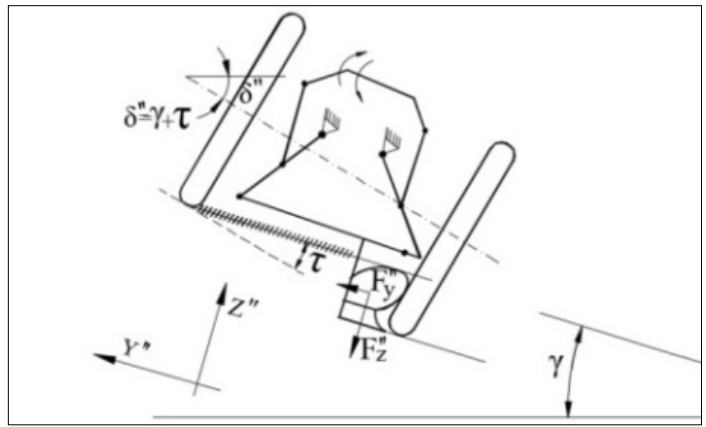

Figure 7. The position of the machine when the furrow is turned downhill

\subsubsection{The torque models}

As shown in expressions (5) and (9), the movement along the contour line causes the change of the lateral forces in comparison with the original setting. Therefore in the $\mathrm{PF}_{\mathrm{H}}$ horizontal instantaneous rotation point a torque arises.

The torque equation is written to the center $O$ of the power machine's rear axle because the coordinates used in the equation are primed relative to this. Let M' the torque in the horizontal instantaneous rotation point when turning at the furrow in uphill. The sense of the torque is supposed on the practices and it is shown on Figure 8.

$x_{G} G \sin \delta^{\prime}+F_{x} y_{G}+F_{y}^{\prime} x_{G}-x_{T} G_{T} \sin \delta^{\prime}-M^{\prime}=0$

where:

$\left(x_{G}, y_{G}\right)$ coordinates of the mass center of the plough [m],

$G$ is the weight force of the plough [N],

$\left(x_{T}, y_{T}\right)$ is the mass center of the tractor [m],

$G_{T}$ weight force of the tractor, [N].

$M^{\prime}=x_{G} G \sin \delta^{\prime}+F_{x} y_{G}+F_{y}^{\prime} x_{G}-x_{T} G_{T} \sin \delta^{\prime}$

When the furrow is turned on the slope, the forces create a torque at the horizontal instanta-

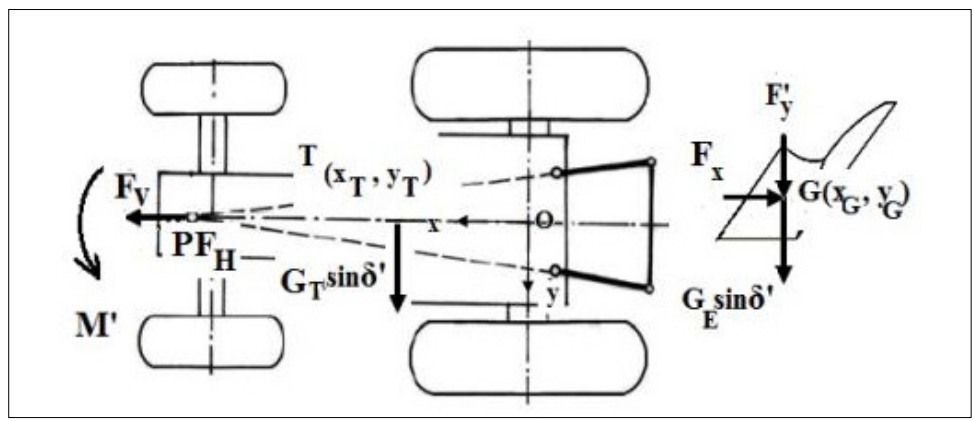

Figure 8. The forces in the machine units when turning the furrow in uphill 
neous rotation point, in the $\mathrm{PF}_{\mathrm{H}}$. The direction of M" is given on the basis of the experienced phenomena, (Figure 9.).

$$
-x_{G} G \sin \delta^{\prime \prime}+F_{x} y_{G}+F_{y}^{\prime \prime} x_{G}+x_{T} G_{T} \sin \delta^{\prime \prime}-M^{\prime \prime}=0
$$

$$
M^{\prime \prime}=-x_{G} G \sin \delta^{\prime \prime}+F_{x} y_{G}+F_{y}^{\prime \prime} x_{G}+x_{T} G_{T} \sin \delta^{\prime \prime}
$$

The rotating phenomenon depends on the weight forces of the plough and the power machine and indirectly on the working depth and width, (11), (13):

$$
\begin{aligned}
M^{\prime} & =f\left(G, G_{T}, y_{G}, F^{\prime}{ }_{y}, F_{x}\right)=f\left(G, G_{T}, a, b\right) \\
M^{\prime \prime} & =f\left(G, G_{T}, y_{G}, F^{\prime \prime}{ }_{y}, F_{x}\right)=f\left(G, G_{T}, a, b\right)
\end{aligned}
$$

\subsection{Numerical evaluation}

Using the mathematical models, we represented the development of the torques in the two case studies as functions of the working depth and width (Figure 10., Figure 11.).
The data used are the dimensions of the PP3-30 plough: $\mathrm{b}=3 \times 0.3 \mathrm{~m}$, weight $\mathrm{G}=5000 \mathrm{~N}$, coordinates of the plough mass center: $x_{G}=1.7 \mathrm{~m}, \mathrm{y}_{\mathrm{G}}=0.3$ $\mathrm{m}$. Specific soil resistance at ploughing on medium soil can be considered to be $\mathrm{k} 0=50000 \mathrm{~N} / \mathrm{m} 2$. [1]. The weight of the tractor is $35000 \mathrm{~N}$, the coordinates of the tractor mass center are $\mathrm{x}_{\mathrm{T}}=0.5 \mathrm{~m}$, $\mathrm{y}_{\mathrm{T}}=0 \mathrm{~m}$, and the angle of the slope is $30^{\circ}$. It can be considered [2] $\mathrm{F}_{\mathrm{y}} \approx 0,33 \mathrm{~F}_{\mathrm{x}}, \mathrm{F}_{\mathrm{z}} \approx 0,2 \mathrm{Fx}$.

\section{Conclusions}

When the furrow is turned uphill, the head of the tractor maintains the direction well. The right-hand wheels of the tractor can lean on the furrow wall; the resulting torque is taken up partially by the furrow wall.

When the furrow is turned down on the slope, a large rotating effect occurs at the instantaneous rotation point. The right-hand wheels of the tractor are not able to lean on the furrow wall, so the torque generated in the instantaneous pivot point must be fully taken up by the steering mechanism, which means that the driver of the power machine experiences difficulty maintaining the direction.

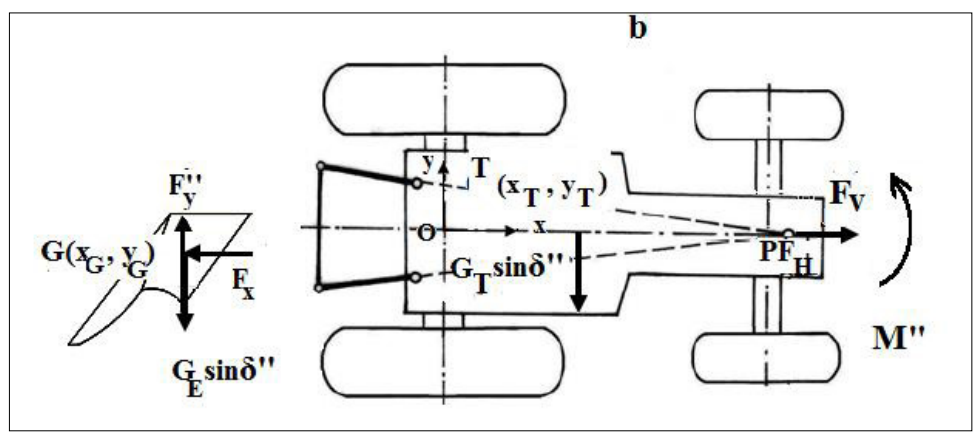

Figure 9. The forces in the machine units on the furrows turning down on slope

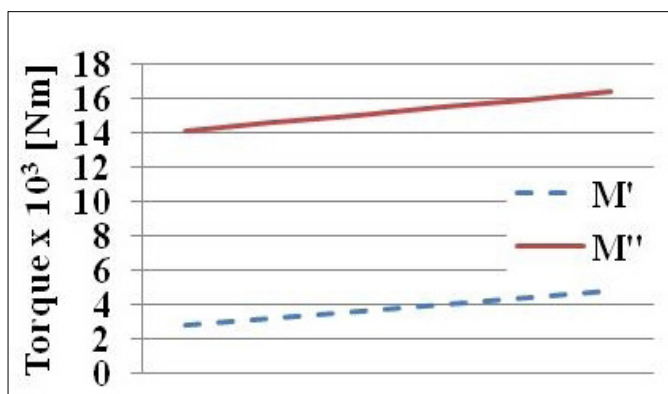

$\begin{array}{llllll}0.2 & 0.21 & 0.22 & 0.23 & 0.24 & 0.25\end{array}$

Figure 10. The torque variation with the working depth

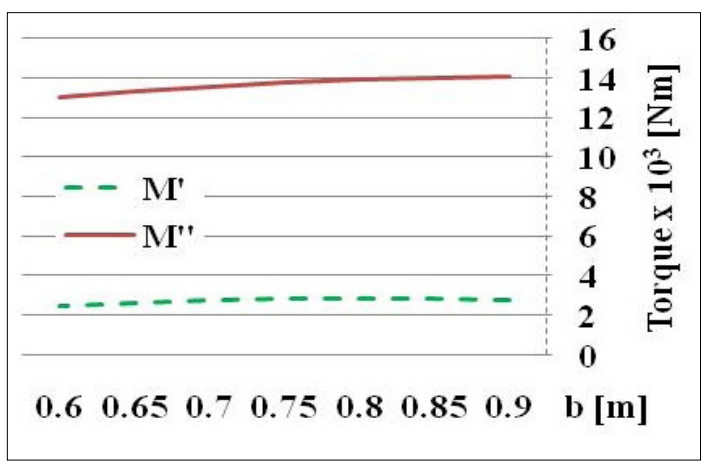

Figure 11. The torque variation with the working width 
If the working depth increases, the resulting torque increases too, in both cases. Reducing the working width the torque generated during plowing will decrease.

The experienced phenomenon focuses the attention on the importance of accurate plough adjustment.

Mathematical models explain the phenomenon and are suitable for further research.

\section{References}

[1] Ormenișan A. N.: Theoretical and Experimental Research Concerning the Influence of Automatic Control Systems of the Tractor Linkage Mechanisms on the Dynamics and Energetics of Plough- ing Units, UTBv, 2014. 19-37. (accessed 2018. jan. 24.)

http://old.unitbv.ro/Portals/31/Sustineri $\% 20$ de\%20doctorat/Rezumate2014/OrmenisanAlexe. pdf

[2] Szendrő P.: Mezőgazdasági gépszerkezettan. Mezőgazdasági Kiadó, Budapest, 2000. 79-82.

[3] Máté, M.: Müszaki mechanika - kinematika. EME Kiadó, Kolozsvár, 2010. 155-163.

[4] Tolvaly-Roșca F., Papp I.: Kinematic Analysis of 2 DoF Spherical Mechanism Applying Constraint Equations. MACRo, Marosvásárhely, Románia, 2015. 235-240. (accessed 2018. jan. 24.)

https://www.degruyter.com/downloadpdf/j/ macro.2015.1.issue-1/macro-2015-0023/macro-2015-0023.pdf 